\title{
Sizing Community Energy Storage Systems - Used for Bill Management compared to Use in Capacity and Firm Frequency Response Markets
}

\author{
Mahmoud Elkazaz*T, Mark Sumner*, David Thomas* \\ * Department of Electrical \& Electronic Engineering, The University of Nottingham, Nottingham, UK \\ ${ }^{\mathrm{T}}$ Department of Electrical Power \& Machines Engineering, Tanta University, Tanta, Egypt \\ mahmoud.elkazaz@nottingham.ac.uk,mahmoud.elkazaz@f-eng.tanta.edu.eg
}

\begin{abstract}
This paper introduces an economic analysis for the optimal sizing of a battery energy storage system (BESS) for use in an Energy Community. The analysis is based on data from a UK community and aims to determine the best size for the BESS to manage the community's electricity bill and enhance the PV self-consumption within the community. The economic study is performed over 20 years. A study is made to determine the financial reward if the community BESS is used instead to participate in UK energy and capacity markets. The results obtained show that investment in BESS for community energy bill management (CEBM) can create the highest internal rate of return (IRR) compared to using the same BESS for capacity/energy market services in the UK.
\end{abstract}

Keywords—Community Energy Storages System, Battery Sizing, Bill management, Capacity Market, Firm Frequency Response.

\section{INTRODUCTION}

The growth of renewable energy sources (RES) in the electricity grid together with the increasing use of electricity for transport and heating, ventilation and air-conditioning require a new vision for future electricity grids. For example the concept of "Community Energy" is gaining credibility within the energy market as a mechanism for aggregating domestic consumers [1]. The term 'Community Energy' can be defined as any energy project that is wholly or partly owned or controlled by a community group [2]. The UK government has encouraged individuals to work as a group and over the last 5 years, more than 5,000 community-led projects have sprouted up across the UK [3]. Besides achieving benefits for community's customers, these communities offer the opportunity to adjust the national network demand/generation through the use of renewable energy resources such as PV panels, Wind Turbines, Demand-Side Management, as well as battery energy storage. On the other hand, there is an increasing trend oriented towards encouraging consumption of energy generated from RES locally at the lowest levels of the grid instead of exporting surplus to the main grid [4]. This trend is receiving increasing attention with the development of domestic energy storage technologies $(<20 \mathrm{kWh})$ as well as large scale energy storage systems (ESS) (>1MWh) and techniques for incorporating these ESS into energy communities architectures.

In recent years there has been much research into sizing approaches for battery energy storage systems (BESS) [5]. For example the optimal sizing of a BESS for both grid-connected and islanded mode are studied [6] whereas optimal sizing of a BESS is determined in [7], considering constraints due to wind power dispatch and investment cost. [8] studied optimal sizing of a BESS by considering various costs associated with the BESS, without considering the operational penalties. In [9] optimal operation of a BESS is discussed but its sizing is not discussed. However, very few studies have been carried which consider an economic analysis and the optimal sizing of BESS in a "behind-the-meter" application. In [10], a BESS is examined for a behind-the-meter application to achieve demand charge reduction. [11] examines various technologies for BESS and assesses their economic viability and impacts on power systems.

This paper explores the economics of sizing a community BESS, either using the BESS directly to reduce consumer bills, or using the system to participate in the UK capacity/energy markets. This paper introduces a proper sizing scheme to select the best BESS size (in terms of energy and power rating) for a community energy storage system considering its economic performance over a 20 year lifetime. This includes an investigation of the potential revenue when using the BESS in National Grid services such as the capacity market (CM) and Dynamic Firm Frequency Response (DFFR) market (these services potentially offer the best revenues from the UK energy market). The main contributions of this work can be summarized as follows:

- It provides a proper sizing for battery energy storage systems for community energy bill management (CEBM) considering economic performance over a 20 year lifetime.

- It compares the economic revenue from participation of the community BESS in UK energy/capacity markets compared to being used for CEBM.

- It studies the effect of BESS sizing on the revenue from using the BESS for CEBM, capacity, and energy markets.

The paper is organized as follows: Section II introduces the architecture of the community energy system considered. Section III focuses on the formulation of the sizing optimization problem including system modelling and constraints. Section IV and V show the economic results obtained. 


\section{COMMUNITY ARCHITECTURE}

The case study used in this paper is a real UK based community which includes distributed (rooftop) Photovoltaic (PV) generation system and a BESS. The community consists of 114 houses with an average daily demand of $2.1 \mathrm{MWh}$. The 500 $\mathrm{kWp}$ distributed Photovoltaic panels generates 1.25 MWh per day. The community is also connected to the main distribution grid to import any additional energy. Fig. 1 shows the architecture of the community. A load power profile (with a one minute sample time) for this community has been created using a model from the Centre for Renewable Energy Systems Technology (CREST) (Richardson and Thompson [12]) for a period of one year. A PV generation profile, again with a one minute sample time has been created, using measured data available at the PVOutput.org website [13] for a $22 \mathrm{~kW}$ PV station located at the University of Nottingham. The PV generation profile is scaled up to give an equivalent average daily generation of $1.25 \mathrm{MWh}$.

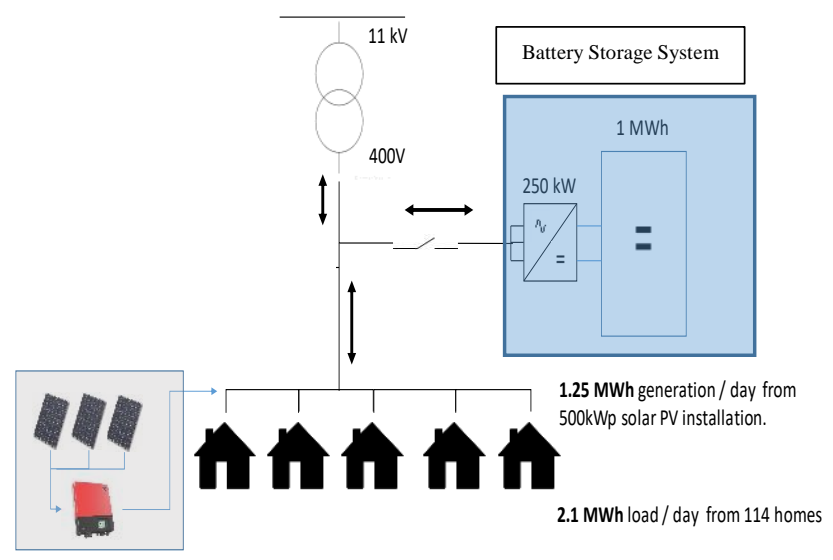

Fig. 1. Community architecture

\section{OPTIMIZATION-PROBLEM FORMULATION}

The optimal BESS size is the size which minimizes both the investment cost of the BESS and the operational cost when used in the community. In this paper, the sizing problem has been formulated as a mixed-integer linear programming problem (MILP) [14]. The objective function which determines the optimal BESS size is formulated in section III $A$, while the constraints are formulated in section III $B$. The output of the optimization process is the optimal capacity rating of the BESS (kWh) and the optimal power rating of the converter used $(\mathrm{kW})$ to connect it to the grid.

\section{A. Objective function formulation}

The objective of the optimal BESS sizing problem for one year is proposed as follows:

$$
\begin{gathered}
\min \left\{\mathrm{CAPEX}_{\text {year }}+\mathrm{OPEX}_{\text {year }}\right\} \\
\mathrm{CAPEX}_{\text {year }}=\frac{\mathrm{IC}_{\text {energy }}}{\mathrm{LF}} \times \mathrm{C}_{\mathrm{B}}+\frac{\mathrm{IC}_{\text {power }}}{\mathrm{LF}} \times \mathrm{P}_{\mathrm{BESS}}{ }^{\text {rated }} \\
\mathrm{OPEX}_{\text {year }}=\mathrm{Y}_{\text {main_cost }}+S C+\sum_{\text {day } 1}^{\text {day }}{ }^{365}\left\{\mathrm{~F}_{\text {buy }}(\mathrm{t}) \times \Delta \mathrm{T} \times \mathrm{PUt}_{\text {import }}(t)-\mathrm{F}_{\text {sell }}(\mathrm{t}) \times \Delta \mathrm{T} \times \mathrm{PUt}_{\text {export }}(t)\right\} \\
\mathrm{Y}_{\text {main_cost }}=0.45 \% \times \mathrm{CAPEX}_{\text {year }} \times \mathrm{LF}
\end{gathered}
$$

where $C A P E X_{\text {year }}$ is the capital investment cost of the battery energy storage system (BESS) (£),OPEX $X_{\text {year }}$ is the operating costs of the community energy system (£), I $C_{\text {energy }}$ is the BESS energy rating investment cost $(\mathfrak{f} / \mathrm{kWh}), I C_{\text {power }}$ is the BESS power rating investment cost $(\mathfrak{f} / \mathrm{kW}), C_{B}$ is the BESS rated capacity $(\mathrm{kWh}), P_{B E S S}{ }^{\text {rated }}$ is the BESS rated power discharge/charge (kW), LF is the BESS Life time (i.e. assumed 20 years), SC is the yearly standing charge price (£/year), $\Delta T$ is the sampling time (h), $P U t_{\text {import }}(t)$ is the daily electrical power purchased from the main distribution grid at a time interval $\mathrm{t}(\mathrm{kW}), P U t_{\text {export }}(t)$ is the daily electrical power exported to the main distribution grid at a time interval $\mathrm{t}$ $(\mathrm{kW}), F_{b u y}(t)$ is the electricity time of use (TOU) purchase tariff at a time interval $\mathrm{t}(\mathfrak{f} / \mathrm{kWh}), F_{\text {sell }}(t)$ is the electricity sale tariff at a time interval $\mathrm{t}(\mathfrak{f} / \mathrm{kWh})$, and $Y_{\text {main_cost }}$ is the BESS yearly maintenance cost $(\mathfrak{f})$.

The capital cost CAPEX $\mathrm{year}_{\text {or }}$ of the BESS is normalized on an annual basis (i.e. distributed over the lifespan of the BESS). The BESS investment cost (2) includes pro-rata installation costs for energy rating $\left(\mathrm{IC}_{\text {energy }}\right)$ and power rating $\left(\mathrm{IC}_{\text {power }}\right)$. The expected operating costs of the community after using the BESS (3) are: (1) the cost of yearly imported electricity from the main distribution grid to feed the community's load demands and charge the BESS, (2) the yearly standing charge cost, (3) the yearly maintenance cost of the BESS (i.e. calculated based on a fixed value $0.45 \%$ of the total investment cost of the BESS [15]), and (4) the revenue of the surplus energy sold to the main grid (i.e. the excess electricity produced by the PV generation after satisfying the community demands and charging the BESS) [16]. 


\section{B. Community and BESS model, and constraints}

The economic model and the constraints of the system considered here can be represented by the following equations:

The balance equation of the total active power in the community is formulated as:

$$
\mathrm{PUt}_{\text {import }}(t)-\mathrm{PUt}_{\text {export }}(t)+\mathrm{P}_{\mathrm{BESS}}(t)=\mathrm{P}_{\text {load }}(t)-\mathrm{P}_{\mathrm{PV}_{-} \text {gen }}(t)
$$

where $P_{\text {load }}(t)$ is the daily electrical load demand of the community energy at a time interval $t(k W), P_{P V}(t)$ is the daily electrical power generated by the PV system located at the community energy at a time interval $t(k W), P_{B E S S}(t)$ is the daily net electrical power discharged/charged by the BESS at a time interval $t(\mathrm{~kW})$, (i.e. $\mathrm{P}_{\text {bat_disch }}(\mathrm{t})-\mathrm{P}_{\text {bat_charge}}$ ); where $\mathrm{a}+\mathrm{ve}$ value means that the BESS discharges, and a -ve value means that the BESS charges.

The simplified model of the BESS used in this research is represented by:

$E(t)=E(t-1)-$

$$
\begin{gathered}
\frac{\Delta \mathrm{T} \times P_{\text {bat_disch }}(\mathrm{t})}{\eta_{\mathrm{d}} \times \eta_{\text {Conv }}}-\Delta \mathrm{T} \times \eta_{\mathrm{c}} \times \eta_{\text {Conv }} \times \mathrm{P}_{\text {bat_charge }} \\
\operatorname{SOC}(\mathrm{t})=\frac{\mathrm{E}(\mathrm{t})}{\mathrm{C}_{\mathrm{B}}}
\end{gathered}
$$

Binary constraints (8-10) are used to avoid charging and discharging the BESS at the same time.

$$
\begin{gathered}
0 \leq P_{\text {bat_disch }}(t) \leq \Phi(t) \times \mathrm{P}_{\mathrm{BESS}}{ }^{\text {rated }} \\
0 \leq P_{\text {bat }_{\text {charge }}} \leq\{1-\Phi(t)\} \times \mathrm{P}_{\mathrm{BESS}}{ }^{\text {rated }} \\
\Phi(t)=\left\{\begin{array}{c}
1, \text { if discharge } \\
0, \text { if charge }
\end{array}\right.
\end{gathered}
$$

where $P_{\text {bat_disch }}(t)$ is the daily electrical power discharged by the battery at a time interval $t(k W), P_{\text {bat_charge }}$ is the daily electrical power charged by the battery at a time interval $\mathrm{t}(\mathrm{kW}), \mathrm{E}(\mathrm{t})$ and $\mathrm{E}(\mathrm{t}-1)$ are the stored energy in the BESS at a time interval $\mathrm{t}$ and $\mathrm{t}-1$ respectively $(\mathrm{kWh}), \eta_{\mathrm{d}}$ and $\eta_{\mathrm{c}}$ are the efficiencies of the battery discharging and charging respectively $(\%)$, $\eta_{\text {Conv }}$ is the power converter efficiency $(\%)$, and $\Phi(t)$ is a binary variable.

Constraint (11) reflects the maximum power that can be charged/discharged by the BESS over a fixed time interval.

$$
-\mathrm{P}_{\mathrm{BESS} \max } \leq \mathrm{P}_{\mathrm{BESS}}(\mathrm{t}) \leq \mathrm{P}_{\mathrm{BESS} \max }
$$

Constraint (12) defines the maximum and the minimum SOC level of the BESS. This constraint is important to the BESS operation and is set following the recommendations of the IEEE [17].

$$
\mathrm{SOC}_{\text {min }} \leq \mathrm{SOC}(\mathrm{t}) \leq \mathrm{SOC}_{\text {max }}
$$

where $\operatorname{SOC}(\mathrm{t})$ is the state of charge of the battery at a time interval $\mathrm{t}(\%), S O C_{\max }$ and $\mathrm{SOC}_{\min }$ are the maximum and the minimum state of charge limit of the BESS (\%) respectively. Maximum and minimum SOC level constraints avoid overcharging or deep discharge of the BESS to maximise the lifetime of the BESS. Overcharging and deep discharging of the BESS significantly reduce battery lifetime.

\section{ECONOMIC ANALYSIS}

A simulation process has been performed to determine the best size of the BESS for CEBM. The results obtained are then used in an economic study to obtain the IRR of this investment over a 20 year period. The IRR of the BESS investment for CEBM is also compared with other cases where the same BESS is used for a CM service and for a DFFR services in the UK energy market. The size of the BESS was then varied to determine the maximum revenue that can be obtained from the participation of the BESS in the energy and capacity markets in the UK. The simulation process is performed using MATLAB software: this simulation uses the minute by minute data for the community load and PV generation, and a battery control algorithm formulated from (5)-(12) to create minute-by-minute power profiles for grid and battery usage which can be allocated to specific charges using a time of use tariff. An economic analysis can then be made using Microsoft Excel. The system parameters and tariff values used in the simulation are shown in Table I [18], [19], [20].

\section{A. Community energy bill management (CEBM)}

From the simulation results using (1-12) for 1 year, the optimal BESS capacity for CEBM is found to be $1000 \mathrm{kWh}$ and the optimal power rating is $250 \mathrm{~kW}$. The local self-consumption of the PV generation within the community increased from 53\%, before using the BESS, to $83.5 \%$. The daily operating cost of the community is reduced from $£ 64,562$, (without the BESS) i.e. the cost of the electricity purchased by the community from the supply utility before using the BESS, assuming a flat rate 
of $13.15 \mathrm{p} / \mathrm{KWh}$ for the whole day - to $£ 33,872$ when using the optimal size of the BESS (i.e. the reduction percentage is 47.5 $\%)$. This percentage reduction is considered the yearly income from investment in using BESS for CEBM.

TABLE I. SYSTEM PARAMETERS AND TARIFF VALUES

\begin{tabular}{|c|c|}
\hline Parameter & Value \\
\hline $\mathrm{IC}_{\text {energy }}$ & $£ 350 / \mathrm{kWh}-£ 500 / \mathrm{kWh}$ \\
\hline $\mathrm{IC}_{\text {power }}$ & $£ 95 / \mathrm{kW}-£ 400 / \mathrm{kW}$ \\
\hline $\mathrm{SOC}_{\min }$ & $20 \%$ \\
\hline$S O C_{\max }$ & $90 \%$ \\
\hline Converter efficiency $\left(\eta_{\text {Conv }}\right)$ & $98 \%$ \\
\hline $\begin{array}{l}\text { Battery charging \& discharging efficiency } \\
\left(\eta_{\mathrm{d}}, \eta_{\mathrm{c}}\right)\end{array}$ & $90 \%$ \\
\hline Battery capacity degradation & $2 \%$ p.a. \\
\hline Inflation rate & $2 \%$ \\
\hline Energy prices increase rate & $5 \%$ p.a. \\
\hline Standing charge (SC) & $80.2 £ /$ year \\
\hline $\begin{array}{l}\text { TOU purchasing tariff (Off-peak) } \\
\qquad \mathrm{F}_{\text {buy }}\end{array}$ & $\begin{array}{l}5 \text { pence/kWh ; From } 12 \\
\text { am to } 7 \text { am }\end{array}$ \\
\hline $\begin{array}{l}\text { TOU purchasing tariff (Mid-peak) } \\
\qquad \mathrm{F}_{\text {buy }}\end{array}$ & $\begin{array}{c}12 \text { pence } / \mathrm{kWh} \text {; From } 7 \\
\text { am to } 4 \mathrm{pm}, \text { and From } 8 \\
\text { pm to } 12 \mathrm{am})\end{array}$ \\
\hline $\begin{array}{l}\text { TOU purchasing tariff (Peak) } \\
\text { F }_{\text {buy }}\end{array}$ & $\begin{array}{c}25 \text { pence/kWh ; From } 4 \\
\text { pm to } 8 \text { pm) }\end{array}$ \\
\hline $\mathrm{F}_{\text {sell }}$ (fixed all day) & 4.85 pence $/ \mathrm{kWh}$ \\
\hline $\begin{array}{c}\text { Capacity market revenue } \\
\text { (contract fees) }\end{array}$ & $£ 16.8 / \mathrm{kW} /$ year \\
\hline $\begin{array}{l}\text { Dynamic firm frequency response revenue } \\
\text { (availability fees ) }\end{array}$ & $£ 8$ /MW /hour \\
\hline Guarantee of BESS response for DFFR & $95 \%$ \\
\hline $\begin{array}{c}\text { Energy services company management } \\
\text { fee }\end{array}$ & $20 \%$ of net yearly profit \\
\hline
\end{tabular}

\section{B. Capacity market (CM) services}

The CM is a mechanism introduced by the UK government to ensure that electricity supply continues to meet demand as more unpredictable renewable generation plants come on stream [21]. The objective of the CM is to achieve long-term security of supply. CM offers fixed yearly payments to generators within the CM and buys capacity (£/kW/year) ahead of delivery. The BESS operation within the CM is based on being instructed to discharge, normally with the rated power, during a fixed time period through the day based on the requirements of the National Grid Operators. The BESS is charged at night (i.e. low purchasing electricity tariff) or from the surplus PV energy during the day. This operation procedure is repeated daily.

The total yearly revenue from using the BESS in CM is calculated in terms of payment and incomes. The payments include (1) charging the BESS at night (i.e. off-peak energy purchase tariff of 5 pence/KWh): the BESS is not fully charged at night so that it can store any surplus PV energy available during the day; (2) the yearly standing charge; (3) the yearly maintenance cost of the BESS, and (4) $20 \%$ of the net yearly profit: this is paid to the Energy Service Company for project management. The incomes include (1) the CM contracted fees $(16.8 £ / \mathrm{KWh} / \mathrm{year})$, and (2) the discharged energy by the BESS to the national grid at a sale price of 11.99 pence/kWh (i.e. only when instructed by the National Grid Operators)

\section{Dynamic Firm Frequency Response (DFFR) services}

The UK National Grid needs energy users to provide frequency response services, where they are expected to act fast and increase, decrease or shift demand, or turn on back-up generation to help stabilise the grid. DFFR services allow a provider to provide a service whereby they may reduce demand or increase generation when instructed by the UK National Grid [22]. DFFR is one of the most valuable balancing services to the UK National Grid on a $£$ /MW hour basis [23]. The UK National Grid buys DFFR services through a monthly electronic tender process. The payment for DFFR participation is made using two terms: the Availability Fee (£/hr) - related to the number of hours of availability from a provider, and the Response Energy Fee (£/MWh) - based upon the actual response energy provided.

The operation of the BESS to provide DFFR service is based on being instructed to charge or discharge, normally with the rated power, for a certain event (i.e. typically the event lasts for 3-4 minutes, Max 30 minutes). As the requirements of the national grid operators, The BESS should be capable of keeping charring/discharge with the rated power for up to 30 minutes. Also, the state of charge of the BESS, while participating in DFFR service, should normally be $50 \%$ to be able to respond to any charging/discharging event. 
The yearly revenue from using the BESS in DFFR is the income from (1) Availability Fee ( $£ 8$ /MW /hour) - it is assumed that the BESS is available 24 hours per day all the year with a guarantee of response of 95\%, and (2) Response Energy Fee the actual cost of the response energy provided by the BESS is $£ 0 /$ year; purchasing and selling electricity tariff from/to the main grid while participating in DFFR have the same value [24]. The payments includes (1) the yearly standing charge, (2) the yearly maintenance cost of the BESS, and (3) $20 \%$ of net yearly profits, which go to Energy Service Company for project management.

\section{INTERNAL RATE OF RETURN (IRR) OVER 20 YEARS}

The IRR over 20 years for the investment in the BESS for the above mentioned three cases will be presented in this section. Also, the effect of using different BESS sizes on the IRR will be studied.

The IRR is a metric used in capital budgeting to estimate the revenue of potential investment over a fixed time period. (13) shows how IRR can be calculated.

$$
\operatorname{IRR}=\sum_{\mathrm{Yr}=1}^{\mathrm{Yr}=20} \frac{\operatorname{Cash}_{\mathrm{t}}}{(1+r)^{Y r}}-\operatorname{Cash}_{0}=0
$$

where $\boldsymbol{C a s h}_{\boldsymbol{t}}$ is the net cash inflow during the period $\mathrm{t}, \boldsymbol{C a s h}_{\mathbf{0}}$ is the total initial investment costs, $\mathrm{r}$ is the discount rate, and $\mathrm{Yr}$ is the number of time period (year)

Table II shows the economic revenue from the investment in a $1000 \mathrm{kWh} / 250 \mathrm{~kW}$ BESS for the three cases under study over a 20 year period. Battery capacity degradation of $2 \%$ per year, and increasing rate of energy prices of $5 \%$ per year have been taken into account for calculating the IRR over the 20 year period. Fig. 2 shows the cash flow for the investment in a $1000 \mathrm{kWh} / 250 \mathrm{~kW}$ BESS over a 20 year period for the three cases considered.

TABLE II. ECONOMIC REVENUE OF THE INVESTMENT IN A 1000 KWH/250 KW BESS OVER A 20 YEAR PERIOD.

\begin{tabular}{|c|c|c|c|}
\hline \multicolumn{4}{|c|}{ 1000kWh/250kW BESS } \\
\hline & CEBM & CM & DFFR \\
\hline Initial investment & $£ 378,960$ & $£ 378,960$ & $£ 378,960$ \\
\hline IRR (20 years) & $7.26 \%$ & $4.49 \%$ & $0.53 \%$ \\
\hline $\begin{array}{c}\text { Return on investment } \\
\text { over 20 years }\end{array}$ & $£ 397,882$ & $£ 236,521$ & $£ 26,051$ \\
\hline Cashback period & 12 year & 14 year & 17 year \\
\hline
\end{tabular}

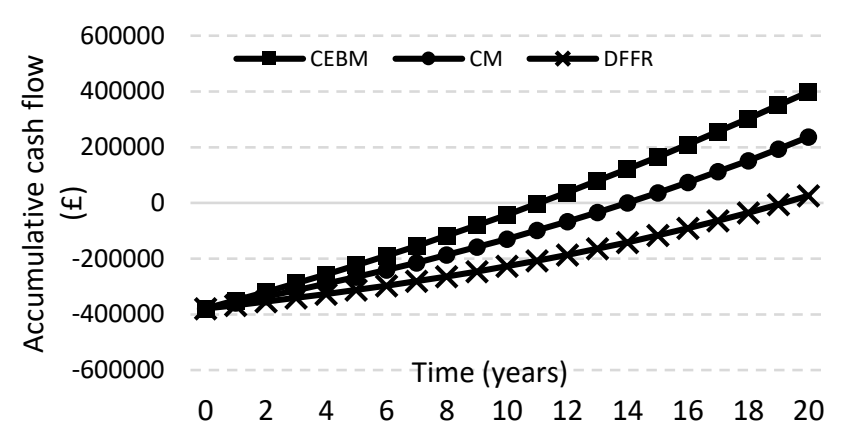

Fig. 2. Cash flow for the investment in a $1000 \mathrm{kWh} / 250 \mathrm{~kW}$ BESS over 20 years for CEBM, CM, and DFFR

It is obvious from Table II and Fig. 2 that using BESS for CEBM provides the largest IRR and also the fastest payback period compared to using the same BESS for other services such as CM or DFFR.

Fig. 3 shows the effect of using different BESS sizes on the IRR while participating in the CM in the UK. The maximum IRR is achieved using the maximum power rating (in this case $1000 \mathrm{~kW}$ ) and the minimum capacity rating (in this case $1000 \mathrm{kWh}$ ) for the BESS. Interestingly, using a BESS with capacities lower than $1000 \mathrm{kWh}$ is problematic in the UK capacity market at the moment since low capacity units face challenges in achieving successful bids. 


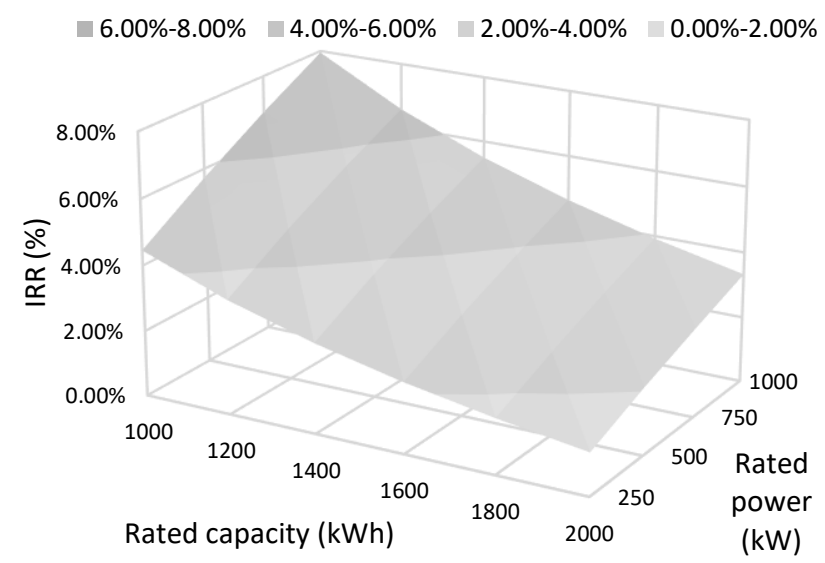

Fig. 3. The effect of using different BESS sizes on the IRR while participating in the CM in the UK.

Fig. 4 shows the effect of using different BESS sizes on the IRR while participating in the DFFR in the UK. Using a BESS of rating $1000 \mathrm{kWh} / 1000 \mathrm{kWh}$ in the DFFR achieves $15.61 \%$ IRR over a 20 year period. This value is high compared to using the same BESS for other services such as CEBM or CM. Again it is interesting to note from fig. 4 that using a BESS of large energy rating and lower power rating will achieve losses to the investment. Power delivery is extremely important for DFFR.

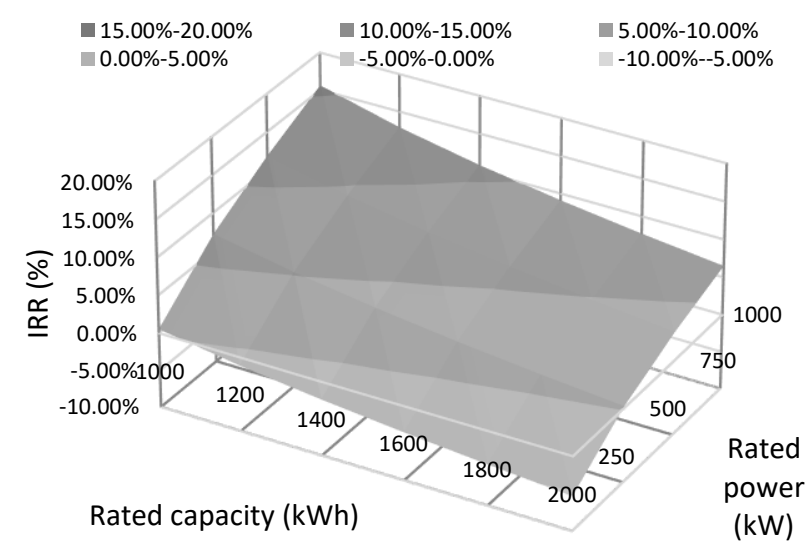

Fig. 4. The effect of using different BESS sizes on the IRR while participating in the DFFR in the UK.

\section{CONCLUSION.}

Optimal sizing for BESS reduces the daily operating cost of the community by up to $45 \%$ compared to the case where no BESS is used. The economic results for a 20 year investment show that using the BESS for community energy bill management achieves more profit (i.e. more IRR) compared to using the same BESS for other services such as capacity market or dynamic frequency response. The results show that a BESS with higher rated power achieves more profits in case of participation in capacity market and dynamic frequency response services. Participation of the community BESS in dynamic frequency response services and capacity market can achieves IRR of up to $16 \%$ and $7.95 \%$ respectively. The results indicate that the life time of the BESS should be as long as possible to obtain a high IRR for the investment in the BESS.

\section{ACKNOWLEDGMENT}

This work is supported by the Egyptian Government- ministry of higher education (cultural affairs and missions sector) and the British Council through Newton-Mosharafa fund.

\section{REFERENCES}

[1] R. Shipman and M. Gillott, "SCENe Things: IoT-based Monitoring of a Community Energy Scheme," Future Cities and Environment, vol. 5, no. 1, 2019.

[2] P. Mirzania, D. Andrews, A. Ford, and G. Maidment, "Community Energy in the UK: The End or the Beginning of a Brighter Future?," 2017.

[3] (2018). Community Energy 2.0: the future role of local energy ownership in the UK. Available online: https://www.greenalliance.org.uk/community_energy_2.0.php

[4] D. Parra, S. A. Norman, G. S. Walker, and M. Gillott, "Optimum community energy storage system for demand load shifting," Applied Energy, vol. 174, pp. 130-143, 2016.

[5] M. Sedghi, A. Ahmadian, and M. Aliakbar-Golkar, "Optimal storage planning in active distribution network considering uncertainty of wind power distributed generation," IEEE Trans. on Power Systems, vol. 31, no. 1, pp. 304-316, 2015. 
[6] X. Yang, J. Chen, L. Zhu, M.-X. Zhang, and H.-B. Wang, "Optimization allocation of energy storage for microgrid based on economic dispatch," Power System Protection and Control, vol. 41, no. 1, pp. 53-60, 2013.

[7] S. L. L. Y. T. Guangyu and S. Nian, "Energy Storage Sizing Method Considering Dispatchability of Wind Farm [J]," Transactions of China Electrotechnical Society, vol. 5, 2013.

[8] B. Bahmani-Firouzi and R. Azizipanah-Abarghooee, "Optimal sizing of battery energy storage for micro-grid operation management using a new improved bat algorithm," International Journal of Electrical Power \& Energy Systems, vol. 56, pp. 42-54, 2014.

[9] D. Parra, S. A. Norman, G. S. Walker, and M. Gillott, "Optimum community energy storage for renewable energy and demand load management," Applied energy, vol. 200, pp. 358-369, 2017.

[10] J. Neubauer and M. Simpson, "Deployment of behind-the-meter energy storage for demand charge reduction," National Renewable Energy Lab.(NREL), Golden, CO (United States) 2015.

[11] B. Dunn, H. Kamath, and J.-M. Tarascon, "Electrical energy storage for the grid: a battery of choices," Science, vol. 334, no. 6058, pp. 928-935, 2011.

[12] I. Richardson and M. Thomson, "Domestic electricity demand model-simulation example," Data Sets and Software (CREST), 2010.

[13] Daily ETB_UoN_Notts_UK 22kW. Available online: https://pvoutput.org/

[14] J. P. Vielma, "Mixed integer linear programming formulation techniques," SIAM Review, vol. 57, no. 1, pp. 3-57, 2015.

[15] P. Ralon, M. Taylor, A. Ilas, H. Diaz-Bone, and K. Kairies, "Electricity storage and renewables: costs and markets to 2030," International Renewable Energy Agency: Abu Dhabi, UAE, 2017.

[16] M. Elkazaz, M. Sumner, S. Pholboon, and D. Thomas, "Microgrid Energy Management Using a Two Stage Rolling Horizon Technique for Controlling an Energy Storage System," in 2018 7th International Conference on Renewable Energy Research and Applications (ICRERA), 2018, pp. 324-329.

[17] "IEEE Guide for Optimizing the Performance and Life of Lead-Acid Batteries in Remote Hybrid Power Systems , IEEE Standard 15612007, pp. C1-25, May 2008.."

[18] Time-of-day purchasing tariff in UK. Available online: https://www.moneysavingexpert.com/news/2017/01/green-energy-launchestime-of-day-tariff---electricity-savings-available-but-gas-remains-pricey/

[19] Limejump secures the majority of the fully Dynamic Volume awarded in the January month ahead tender. Available online: https://limejump.com/limejump-secures-57-of-january-ffr-auction/\#more-7518

[20] Capacity Market auction parameters: letters from BEIS to National Grid ESO, July 2019. Available online: https://www.gov.uk/government/publications/capacity-market-auction-parameters-letter-from-beis-to-national-grid-eso-july-2019

[21] Understanding the Capacity Market. Available online: https://www.engie.co.uk/wp-content/uploads/2016/07/capacitymarketguide.pdf

[22] Profiting from Demand Side Response. Available online: http://powerresponsive.com/wp-content/uploads/2016/11/ng_meuc-dsrbook.pdf

[23] Getting paid for Firm frequency response (FFR). Available: https://www.nationalgrideso.com/balancing-services/frequency-responseservices/firm-frequency-response-ffr?market-information

[24] System Sell \& System Buy Prices for participation in DFFR services. Available online: https://www.bmreports.com/bmrs/?q=balancing/systemsellbuyprices 